\title{
The Representation of Bangladeshi Migrants in Transit and the Question of Cultural Difference: A Critical Perusal of Ronny Noor's Snake Dance in Berlin
}

\author{
Ritushmita Sharma \\ Ph.D Research Scholar, Department of English, Dibrugarh University, \\ ritu920ct@gmail.com, Orchid idhttps://orchid.org/oooo-ooo2-2979-681o
}

\begin{abstract}
Migration can be conceived as one of the strongest and remarkable signifiers in order to describe the distinguishing features of human beings in the present scenario. With the rapid increase in industrialisation and urbanisation, thousands and thousands of people from the third-world countries are seen to be migrating in search of a new life or opportunities. So, it can be said that the phenomena of migration appear to exert influence upon every nook and crannies of the world thereby becoming the crucial part of contemporary societies. However, the experience of migration brings forth the emergence of migrant identities that undergoes displacement and deracination not only in terms of geographical boundaries but also in terms of cultural bereavement. This as a result enables us to understand the intricacies of hyphenated and hybrid migrant identities that they become due to their realisation of cultural difference. It is on this ground that the present analysis aims to throw light to the case of Bangladeshi migrants in the German city as depicted by Ronny Noor in his novel Snake Dance in Berlin (2009) and thereby to identify the subtle nuances of immigrant psyche. While doing so, the research paper also attempts to observe the circumstances under which the Bangladeshi migrants lived or the strategies deployed by them in order to adjust with a socio-cultural environment which seems to be in sharp contrast to the country of their origin
\end{abstract}

Keywords:migration, immigrant, displacement, Bangladesh

Famous renowned French sociologist Francois Dubet developed a critical and nuanced analysis to the question of cultural difference. He states in his Immigrations (1989) that “. . immigrants are torn between two cultural and social worlds, that they wish to enter into the new world without losing their identity to transform themselves whilst remaining faithful to themselves" (p.59). This statement implies the duality or the sense of ambivalence one witness while migrating from one's own native land to an alien one. Thus, those who migrate they not only experience the diversity of cultures, ethnicities and races but also these factors as a whole which in full length impacts upon their sense of self, place and identity.

It is a well-known fact that Bangladesh during 1970 and 8 os was struggling to gain some form of democratic establishment from the brutal reality of chaos that it once witnessed. It was undoubtedly a time of crisis where for the migrant the image of 'home' could possibly be imagined in terms of a more personalised and idiosyncratic recollections of their past life. As Bibhash Choudhury rightly quotes Willem Van Schendel in his article titled "Ronny Noor: Snake Dance in Berlin" who argues about the turmoilic situation in Bangladesh and how the country

(C) AesthetixMS 2019. This Open Access article is published under a Creative Commons Attribution Non-Commercial 4.0 International License (http://creativecommons.org/licenses/by-nc/4.o/), which permits non-commercial re-use, distribution, and reproduction in any medium, provided the original work is properly cited. For citation use the DOI. For commercial re-use, please contact editor@rupkatha.com. 
attempts to strike a right balance between the institutions of the state and the politics of those who belongs to the authority:

In Bangladesh, the 1970s were in many ways a replay of the 1950s: high hopes for democratic control were soon dashed as the state struggled through increasingly authoritarian civil rule before finding its feet after an army take-over. (Van Schendel, 2009, p.195)

In the year 1971, Bangladesh gained its independence but that too under the most difficult situations. Much of the land's foundation was either wrecked or badly destructed. As a result, in every situation the population of the land suffered the worst consequences and later on scattered as refugees. Nevertheless, apart from violence, there are many other reasons like: Bangladesh being more accustomed to natural disasters, climate change, poverty and unemployment etc. further aggravating their sense of vulnerability and later on motivating their decision to migrate. Therefore, it is assumed that those who leave their natal homes just with the desire to secure a better life in an alien space seems to acculturate more easily. This is what we get to observe in Ronny Noor's Snake Dance in Berlin as well which explores and represents the lives of Bangladeshi migrants seeking political asylum in foreign countries to escape the difficult life that they once lived in Bangladesh.

Ronny Noor's Snake Dance in Berlin presents us with kaleidoscopic view of Bangladeshis who lived in Berlin during the second half of the 1970 and the first half of the 1980s. In the novel, we get to see how their lives get enmeshed in the more complicated mazes of struggle which constantly reminds them of their liminal existence in an alien space, a space which they neither can quit nor claim as to be their own. The different struggle they go through daily is a reflection about their insecurity, in-betweenness and dislocation emerging from their belongingness to Bangladesh, which they once addressed as 'home'. However, we also cannot ignore the fact that for most of the characters in this novel, Berlin serves as a space of retreat, a site of transit or a stopover where they would like to prolong their stay.

In the novel, the displaced Bangladeshis in order to present a sense of unity organises The Golden Boys' Association so that they might take up the political asylum route to gain entry into the German world. Of course, this new space is not something they are finding worth-living, but as migrants from a conflictual land, Berlin at least secures them sense of safety even though the scope of assimilation seems hardly possible. In this context, Rayhan the protagonist of the novel, also narrates the socio-cultural barriers in terms of language, economy, infrastructure that the Bangladeshi migrants encounter on a daily basis which speaks about the implicit tension amongst them and accordingly mirrors the grief-stricken predicament of them in Berlin.

Rayhan is the narrator protagonist of the novel and at the same time the author's mouthpiece who puts forward the worldviews of the Bangladeshi migrants and their sense of uprootedness. It has been shown that the world to which these migrants stepped in is the one where their inherited values and beliefs are in complete contradiction with the cosmopolitan and European way of life, which in turn may make them bound to renegotiate their sense of location and identity. However, Rayhan who have been in Berlin for so many years did not confront any serious problem on being accustomed to the practices and life style of this new world. But for those who are fresh migrants, they had to come in contact with and battle against Janus-faced problems of the mainstream Berlin community which envisions them in the periphery or parenthesises them as a small part of the diasporic Bangladeshi population. 
In this context, we may refer to Homi Bhabha's The Location of Culture (1994) wherein he posits the concept of hybridity in order to explicate the interconnectedness or the intermingling of cultural signs and symbols (meaning different practices and beliefs of a particular culture) from both dominating and marginalised cultures. Bhabha further states that immigrant assimilation into a new country is a complex process for it produces the hybrid postcolonial subject which opts to "negotiate the interstices of Western discursive systems, operating in-between the dichotomies of coloniser and colonised, self and other, East and West" (Bracken, 1998, p.506). This projection of postcolonial hybrid subjects is explored by Noor as well in his depiction of the exiled people from Bangladesh and their integration into the multifaceted Berlin society. Berlin, for the members of the displaced group, represents or connotes different interpretations. While for some of the expatriates, they could easily crystallise into the social fabric and parameters of Berlin society, but there are some who operated within a much-restricted social space. However, Berlin as represented to us in the words of Rayhan is not one of unwelcoming or antisocial sort but the limited opportunities of employment, poor condition of living for the exiled group aggravates further their feeling of dislocation and their sense of being in the Berlin world as outsiders.

The dilemma of in-betweenness and the engrossment as outsiders compels them to make their transvaluation of where they belong to, or where they come from. So, it can be said that they are outsiders in a twofold manner: firstly, their experience as newcomers and the new sense of place have transfused within them a new way of perceiving their homeland; and secondly, in their encounter with the Berliners, they are recognised as part of the exiled Bangladeshi populace. In both the experiences, they are under exposure to a world where they daily struggle to make sense of their activities. Moreover, the Bangladeshi diaspora in Berlin and their formulation of Golden Boys' Association to promote their unity in a foreign land is also brimming with intramural complexities. In other words, if we view the organisation on a very surface level, it might appear to be a unified entity but being constituted of people without any single coherent attitude indicates their multiple social backgrounds and their prolonged disagreement to propose any fixed credo or doctrine. To cite as an instance from the novel, we may refer to Jafar Khan and Kabir Ahmed and their individual fight to get elected as the President of the Golden Boys' Association. This is followed by many attempts enunciated by members like Jafar, Ashok and Malekshah who tried to break away from the organisation too.

Now coming to the central character of the novel Rayhan who comes to Berlin in 1978 so that he may pursue his career in computer science had to face many unanticipated challenges initially. But in Rayhan's case, his problems like facing day to day criticism of being an outsider empowered him more to see things positively and in different manner. For example,Rayhan says in a casual conversation:

You won't find two societies exactly the same. And if you don't know a society, you will always find it strange and frightening from afar. But once you know it, it's a different story. (Noor, 2009, p.25)

Again, to quote Bibhash Choudhury in this context, he writes about Rayhan and his newly achieved sense of identity in the following manner:

... Rayhan's ability to locate himself as the subject of critique presents him with the unique opportunity to carry forward the culture of openness, which isn't quite the characteristic of many in the circle he occupies. This awareness of the fact that there are multiple worlds out there, each with its own internal conditions and social parameters ... It is an awareness of the multicultural social fabric that 
separates him from his contemporaries. Rayhan's perspective thus grants the narrative a unique distinction, one through which the representation emerges as both - a picture of Bangladeshi migrant society and a critique of that culture itself .

.. (Noor, 2009, p. 214)

A sense of cultural difference is achieved by a person when he or she gets a chance to identify the remarkable difference between one's sense of shared set of beliefs and one's actual experience. In case of Rayhan, his first love interest with a girl named Carolina in Berlin changes his perspective about women of two different cultures. For instance, before the relation between them could proceed a few steps further into something promising, Carolina quite clearly states to Rayhan that she is a divorcee and now working as a prostitute. Here Rayhan could realise the cultural difference which places both of them in two complete different and oppositional cultures. He is not unaware of the fact that most women's lives in Bangladesh are only centred on their traditional role-play and accordingly they have much restricted access to education and opportunities. But his experience with Carolina presents to him a different representation of women and their sense of female autonomy. Furthermore, Rayhan's naivety during his lovemaking scene with Carolina offers us a glimpse of not only his socio-cultural background but also the typical mindset of a Bangladeshi family. Rayhan says:

In the place I was born, a middle-class child is brought up to get some kind of education. That comes first. Then he must get a job and only then find a wife for himself.

Sounds like a humdrum life (Noor, 2009, p.70)

After being ended up his affair with Carolina, Rayhan announces his marriage to another girl named Renata wherein again cultural difference imperils their connection. As it has been indicated that Rayhan's family asked him to give up upon his decision to marry Renata and then settle down with a girl from his community back in Bangladesh. However, his non-conformity to his family's decision and then choosing a life with his girlfriend gestures at his challenge to patriarchal ideologies in Bangladesh, and also his cross-examination of the social fabric of Bangladesh as a 'nation'. Rayhan's decision to marry Renata is something debatable in a space like Bangladesh. Therefore, he decides to cope up with his separation from a place which once he called 'home' and then subsequently his sense of discovery empowers him to subscribe into a space and ideology which is ordinarily accepted in Europe.

Ronny Noor's Snake Dance in Berlin does not inform us with any prehistory or any other specific circumstances under which people like Rayhan migrated to Berlin. But the experiences of their already lived world back in Bangladesh finds its traces in their present world through many references and allusions which as a whole suggest the strong presence of Bangladeshi imagination in the represented space in Berlin. This we get to realise in case of Rayhan whose cultural background as a Bangladeshi middle-class boy and now as an engineer in Berlin capacitates him to see the binary between the two different cultures.

Along with Rayhan, the variegated perspectives amongst the Bangladeshi refugees are also reflective of the cultural difference due to which their worldviews clash. Thus, we get to encounter the glimpses of a wide range of individual distinctions which in a way endows us with hints of how a Bangladeshi migrant visualises the world around him, or the society to which he is now newly relocated. Now to substantiate this idea from the text chosen to study, we may refer to the conversation between Kabir Ahmed and Rayhan: 
"Actually son, celebrating birthdays is a European ritual ... These people have to celebrate birthdays, wedding days, father's days, mother's days, and God knows what other days." ... "Why do they have to celebrate Father's Day or Mother's Day?" ... "Because they need to remind themselves that they have fathers and mother's lying in ... what do they call them here, those dungeons for retired people?"

\section{"Altersheim"}

"Yes, altersheim. Otherwise they forget those poor old souls." After a moment of deliberation, picking his nose: "If they keep their aged parents with them as we do..."

"Do we do it willingly? Or because we have to ..."

"We have to do it because we have no other choice. Where will the old parents go? There are no rest homes in our delta." (Noor, 2009. P. 47-48)

This above instance juxtaposes the remarkable difference between the opinion of two individuals and their different sense of belonging. In the words of Kabir Ahmed, he represents his intention to vent out against the European way of life and their ritual of celebrating birthdays. It has been shown further that how these two people Rayhan and Kabir Ahmed undertakes and responds to the question of altersheim. This in a way signals out the contrasting nature in the worldviews of the Bangladeshi people living in the diaspora.

The circumstances of living in a diaspora and at the same time attempting to make sense of their identity form the crux of Ronny Noor's Snake Dance in Berlin. In this context, it becomes crucial to understand the fragile and faded sense of nationalism among the Bangladeshis in diaspora and their sense of nation which they construe after their arrival in Berlin. For example, the case of Bangla people who are in now Berlin and their newly achieved elite sense of living standard gives us their perspectives of Berlin and how they view things back home. However, this is not suitable in the case of tourist or any other travellers who visits a place for official purposes as they cannot dislodge themselves from their identities of a nation which they address as home.

For those living in diaspora, their imagination of home is motivated by their memory, letters, personal recollections, stray visits or Bangla magazines that they receive in Berlin which contributes to the enhancement of their vision of a nation. In this regard we may refer to Rayhan's conversation with an engineer from Dhaka and his representation of Bangladesh that falsifies our narrator protagonist's perception about the welfare designs of the government in Bangladesh. This is best illustrated in the following example:

I understood from his trip to Berlin and also the telephone calls were at government expense. "It must be an interesting life . . . the life of a government representative"

"You can go places, stay in the best hotels, and see objects of interest. Especially now, when we are modernising things. Our country is developing at lightning speed... There are many new buildings, many new cars, and you can see shops full of electronic goods ..."

"All foreign. Imported ... How many can buy them? Not even ten percent of the people. Doesn't development mean that more people get the benefit of 
education and medical care, more people find jobs and earn better every year, live a better life than in the past?" (Noor, 2009, p.206)

For the diasporic community, the concept of nation cannot fully be reconfigured from a distance as the snippets or the images that formulates the version of home country is enfolded within the confines of memory. In this context we may refer to AzadeSeyhan who in his Writing Outside the Nation points out about diasporic life and how the construct of nation cannot be fused and integrated from distant. According to AzadeSeyhan:

The participation of diasporic subject in the cultural life of the host country registers the moment when other literary and artistic forms of expression enter (Western) history. Through this dialectic, the distance between the ports of departure and arrival appears to collapse; the migrant, exile, or voyager not only crosses the threshold into another history and geography but also steps into the role of an itinerant cultural visionary. (14)

Similarly, in the narrative of Snake Dance in Berlin, the notion of nation is construed through fragmented and disconnected facades which fail to depict the fulfilled sense of home and belonging. It is for this reason that the sentiment of nationalism or nationalistic consciousness not only oscillates but also renegotiation of entities like home or nation takes place. This can be seen in the failure to maintain unity by the organisation titled The Golden Boys' Association which may serve as one of the finest examples in this line of thought.

The initiation of The Golden Boys' Association in Berlin by the migrant Bangladeshi population minutely details about the trials and tribulations of keeping themselves as one unit. But at the same time, we are also unaware about the strategies deployed by Kabir Ahmed, the President of the organisation against the two members of the same association. He organises an attack and while scheming it, his aim is underpinned by the motive to retain supremacy among the rest group members. This is also assured to us by Rayhan in the very beginning indicating Kabir Ahmed's desire to sustain the hierarchy among the newcomers to Berlin. Here we can refer to one such example wherein Rayhan explains about Kabir Ahmed's proposed rules and regulation about the Association which facilitate him to get an upper hand:

The constitution of our Association did not bar persons without knowledge of German or those seeking political asylum from being elected to the executive committee. Such questions had not arisen in 1974, when the Association was founded by a handful of Bengali students; there were no asylum seekers then in Berlin. But there were now, and quite a few. (Noor, 2009, p.8)

Although many resisted against Kabir Ahmed's efforts, but he took authority via his own formulated rules and regulation. It is ironical that Kabir Ahmed who arrived in Berlin without having any knowledge of the German language, and also with the fear of being expelled from the land at any moment now aims to envisage upon a life back in Bangladesh and hope to join Bangladeshi politics. This displays the frangible nature of diasporic identity in question. Here we may again refer back to the case of Kabir and the arrival of a letter in the name of his address but the letter remains unaddressed and therefore retracted back to the post office. Till this point of life, Kabir is living his life in Berlin only with the aid of his business card. He is too without any proper identity proof but hopes to achieve some space in this new city which is bit incongruous. With reference to the letter, Kabir says:

“Then how will you get your registered letter?" 
"I have my business card."

"Oh God! That blasted card doesn't mean a thing to them. They'll want to see your valid passport."

"Why?" he looked full at me, stopping suddenly in the middle of the sidewalk, forcing passersby to make a detour. "You mean my card isn't valid? Am I a tinhorn or something? My name as President of our Association has been registered with the court. It's a legal organisation." (Noor, 2009, p.202)

The city of Berlin is marked by its own character. On the one hand, Berlin is represented as embracing and welcoming for its cosmopolitan character accommodating people from all over the world. On the other hand, the city asked to fulfil certain demands which not everyone could hope to do so. As a result, the displaced migrant community in Berlin struggles to negotiate their life and identity in unison with their present lifestyle. Characters like Tera Reza who runs away to Berlin and becomes a dishwasher; there is Saad who is recognised as a romantic poet-philosopher in the community but eventually commits suicide, and then Kabir whose asylum application has been rejected seems to occupy a marginal space in Berlin. In case of Kabir, he never paid any attention to the German language. It has been pointed out how Kabir "refused to acclimatise himself to the circumstances of the society in which he lived and operated . .." (Beyond Cartography 234). Moreover, the other outsiders who are not fluent in conversation with German culture and language, life for them turned out to be more worrisome. To cite an example from the text, we may refer to Tiger Amir who got rejected by his girlfriend Angelika on account of his negligence to acknowledge and admire German culture. Here Rayhan says to Amir and speaks about how culture varies in terms of different places:

Well, in Dhaka you would do what many rich youths like you do for unrequited love. Cut yourself short. Or wear pajama ... wrap yourself in gamcha . . . and walk the streets like a tramp with unshaven stubble . . . But my advice is: take things easy, Tiger. Behave like a Roman when you're in Rome. (Noor, 2009, p.34)

The statement of Rayhan that "Behave like a Roman when you're in Rome" poses question about the nature of displacement of the migrant Bangladeshi population. The inability to understand or their failure to fit into the custom and traditions of German culture contributes much to their crisis. While for Rayhan Berlin is his space of freedom, but for the rest, they conceive it to be a more enclosed kind of space which further pushes them into a more self-imposed constricted world. Rayhan states that Berlin in many ways rendered freedom to its immigrants and ready to harbour one and all: "Berlin used to be good, it's true. It did not make Croesuses out of paupers or Shah Jahans out of beggars, but it opened its generous arms of hospitality to thousands from every nook and cranny of the world, even the communists" (Noor, 2019, p.224). Thus, it can be said that out of all, only Rayhan seems to adjust himself with the temperament of Berlin. Not to deny the fact that Rayhan was too aware of the stark contrast between his present living culture and the one which he lived and then left. But he forever remained quite at ease as he could without any obstruction internalise and adapt with the new culture which was not possible for many of the other exiled Bangladeshi population. 


\section{References}

Allatson, Paul and McCormack, Jo. (Eds.). (2008). Exile Cultures, Misplaced Identities. Amsterdam: Rodopi.

Baker, Brenda J and Tsuda, Takeyuki. (Eds.). (2015). Migration and Disruptions. Gainesville:University Press of Florida.

Bhabha, Homi. (1994). The Location of Culture. London: Routledge.

Boehmer, Elleke. (2005). Colonial \& Postcolonial Literature: Migrant Metaphors. Oxford:OUP.

Bracken, Christopher. (1998). Encyclopedia of Semiotics. UK: Oxford University Press.

Choudhury, Bibhash. (2011). Beyond Cartography: The Contemporary South Asian Novel inEnglish. Guwahati: Papyrus.

Dickinson, Eliot. (2017). Globalization and Migration: A World in Motion. London and NewYork: Rowman and Littlefield.

Dubet, Francois. (1989). Immigrations. Paris: La Documentation Françhise.

Noor, Ronny. (2009). Snake Dance in Berlin. New Delhi: Orient Blackswan.

Pemberton, Kelly and Nijhawan, Michael. (Eds.). (2009). Shared Idioms, Shared Symbols, andthe Articulation of Identities in South Asia. London and New York: Routledge.

Philllips, Douglas A. and Gritzner, Charles F. (2007). Bangladesh. New York: Chelsea house.

Rai, Rajesh and Reeves, Peter. (Eds.). (2009). The South Asian Diaspora: TranslationalNetworks and Changing Identities. London and New York: Routledge.

Ranasinha, Ruvani. (2007). South Asian Writers in Twentieth -Century Britain: Cultures in Translation. Oxford: Clarendon Press.

Seyhan, Azade. (2001). Writing Outside the Nation. Princeton: Princeton University Press.

Silverman, Maxim. (1992). Deconstructing the Nation. London and New York: Routledge.

Van Hear, Nicholas. (1998). New Diasporas: The Mass Exodus, Dispersal and Regrouping ofMigrant Communities. London: UCL PRESS.

Van Schendel, Willem. (2009). A History of Bangladesh. Cambridge: Cambridge University Press.

Welshman, John. (2006). Underclass: A History of the Excluded 1880-200o. London:Hambledon Continuum. Zeng, Hong. (2010). The Semiotics of Exile in Literature. United States: Palgrave Macmillan.

Ritushmita Sharma is a Ph.D Research Scholar in the Department of English, Dibrugarh University, Dibrugarh, Assam. She did Masters Degree and M.Phil from the Department of English, Dibrugarh University. Currently, She is working on Kinopolitics in the field of Migration Literature in the Works from African diaspora 